\title{
Exploring the Need for Developing Impact-Based Forecasting in West Africa
}

\begin{abstract}
Elias Nkiaka ${ }^{1 *}$, Andrea Taylor ${ }^{1,2}$, Andrew J. Dougill ${ }^{1}$, Philip Antwi-Agyei ${ }^{3}$, Elijah Adesanya Adefisan ${ }^{4,5}$, Maureen A. Ahiataku ${ }^{6}$, Frank Baffour-Ata ${ }^{3}$, Nicolas Fournier ${ }^{7}$, Victor S. Indasi ${ }^{4}$, Oumar Konte ${ }^{8}$, Kamoru Abiodun Lawal ${ }^{9,10}$ and Awa Toure ${ }^{8}$

${ }^{1}$ School of Earth and Environment, Sustainability Research Institute, University of Leeds, Leeds, United Kingdom, ${ }^{2}$ Leeds University Business School, University of Leeds, Leeds, United Kingdom, ${ }^{3}$ Department of Environmental Science, College of Science, Kwame Nkrumah University of Science and Technology, Kumasi, Ghana, ${ }^{4}$ African Centre of Meteorological Applications for Development (ACMAD), Niamey, Niger, ${ }^{5}$ Department of Meteorology and Climate Science, Federal University of Technology, Akure, Nigeria, ${ }^{6}$ Ghana Meteorological Agency, Accra, Ghana, ${ }^{7}$ Met Office, Exeter, United Kingdom, ${ }^{8}$ Agence Nationale de l'Aviation Civile et de la Météorologie, Dakar, Senegal, ${ }^{9}$ Numerical Weather and Climate Prediction Unit, Nigerian Meteorological Agency, Abuja, Nigeria, ${ }^{10}$ African Climate and Development Initiative (ACDI), University of Cape Town, Cape Town, South Africa
\end{abstract}

While conventional weather forecasts focus on meteorological thresholds for extreme events, Impact-Based Forecasts (IBF) integrate information about the potential severity of weather impacts with their likelihood of occurrence. As IBF provides an indication of local risk, there is an increasing uptake of this approach globally. Despite the vulnerability of West Africa to severe weather, and the potential benefits of such a risk-based approach for informing disaster risk reduction, IBF remains rarely used in this region. To meet this need, three national workshops were held in Ghana, Nigeria and Senegal with forecasters, project researchers and users of Climate Information Services (CIS) from key sectors (e.g., agriculture, water resources, disaster, risk reduction). In addition, a more localized district level workshop was held in Northern Ghana to explore needs at a subnational scale in Tamale District. The objectives of these workshops were to evaluate the current use of forecast products provided by National Meteorological and Hydrological Services (NMHSs) and to explore the potential for applying IBF. Findings indicate a recognition that the quality of forecast products provided by NMHSs in West Africa has substantially improved in recent years. However, challenges remain related to user understanding, clarity about forecast uncertainty, insufficient spatial and temporal resolution of forecasts leading to limited trust in forecasts. The workshops identified high demand for weather information related to storms, droughts and heatwaves in all the three countries. Dust storms were identified as having strong potential for IBF application in both Nigeria and Senegal. To increase the uptake of CIS by users in West Africa, NMHSs will need to develop and implement user-tailored IBF in their normal weather forecast approaches and improve communication channels with user communities. There is an urgent need for governments in West Africa to enhance the capacity of NMHSs to incorporate IBF as a routine forecast activity by first establishing a National Framework for Climate Services with user engagement as a key first pillar.

Keywords: disaster risk reduction, forecast evalution, stakeholder engagement, climate services, sub-Saharan Africa (SSA) 


\section{INTRODUCTION}

Climate information services (CIS) aim to provide climate information in a way that assists decision-making by individuals and organizations (Allis et al., 2019). Effective integration of weather and climate information into societal decision making processes can build resilience to climate shocks across Africa (Jones et al., 2015; Nkiaka et al., 2019). The development of fit-for-purpose CIS is crucial for managing risk in climatesensitive sectors such as agriculture, water resources, disaster risk reduction (DRR), and health (WMO, 2017; Machingura et al., 2018). Although developing countries have been slow to develop and implement strategies to mitigate natural disasters such as droughts, floods, storms and extreme temperatures, they are already more affected by weather and climate-related disasters as a result of their vulnerability and lack of adaptive capacity (Padli et al., 2018). This is particularly the case in sub-Saharan Africa (SSA) (Azzarri and Signorelli, 2020). Evaluating the quality of CIS provided to users in SSA is therefore of critical importance, as is identifying those weather events that pose the greatest threat to lives, well-being and socioeconomic development. It is argued that the use of CIS in DRR is an integral part of broader development planning (Street et al., 2019), with the provision of CIS to support the management of floods and droughts being an integral part of water resources management.

Within the published CIS literature there are comparatively few studies evaluating the quality of climate and weather information provision in SSA from a user perspective (Daly et al., 2016; McKune et al., 2018). A lack of user evaluation of the quality of climate services in SSA like in other regions may be attributed to the traditionally science-driven approach common in CIS production instead of a demand-driven approach (Brasseur and Gallardo, 2016). Notwithstanding, improving the quality of CIS to match users' needs has been highlighted as a key challenge for the successful implementation of the Global Framework for Climate Services (Hewitt et al., 2012). Results from previous studies in SSA show that evaluating the quality of CIS can offer numerous advantages. For example, evaluating the quality of CIS provided to users in Tanzania has led to the adoption of a national steering mechanism for climate services, highlighted a need to raise awareness among members of the public on the concept of climate services as well as efforts to enhance the delivery of climate information and also highlighted that perception of the credibility of CIS is critical for increasing users' satisfaction (Daly et al., 2016). Another study evaluating how CIS provided to farmers in Senegal and Kenya are used revealed that the timely availability of good quality CIS may lead to the adoption of better agricultural practices (McKune et al., 2018). However, most of the studies evaluating the quality of CIS provided to users in SSA have targeted the agriculture and food security sector (e.g., Coulibaly et al., 2015; McKune et al., 2018; Vaughan et al., 2019), while other sectors such as water resources management and hydropower, disaster risk management and the health sectors have received less attention. Our current study was undertaken with the aim of enriching the CIS evaluation literature in SSA by examining the alignment between CIS provision with the needs of the users in different sectors in three West African countries.
Our study also fills an important knowledge gap by evaluating the quality of CIS provided to users in other sectors which have received less attention in the past.

Effective climate risk management strategies have the potential to lessen the impacts of disaster risks and contribute to boosting resilience globally (Mysiak et al., 2018). This can be achieved through the use of CIS across all phases of a DRR cycle which include disaster mitigation, preparedness, response, and recovery (Lamond et al., 2019). Communication plays a critical role in the dissemination of warnings and the coordination of relief operations for disaster risk management (ITU, 2013). Recognizing this, the UN emphasizes the role of early warning systems for climate and weather hazards in the Sendai Framework for Disaster Risk Reduction 2015-2030 (UNISDR, 2015). Other studies have equally highlighted a need for weather warnings that can enhance public perception of personal risk and promote a rapid and effective public response (e.g., Drost et al., 2016). This has led to the development of Impact-Based Forecasting (WMO, 2015) which is intended to improve risk communication by using a targeted communication strategy concerning the hazard, source, and impact of the forecast event with clearly identified potential threats (Drost et al., 2016). We posit that Impact-Based Forecasting could represent a significant opportunity for the enhanced provision of CIS in the disaster risk management sector, with warnings being linked to the potential harm that specific severe weather events may cause.

This paper reports on the findings of four workshops held across three different West African countries [Ghana (including both national and sub-national workshop), Nigeria and Senegal]. These workshops were undertaken to conduct a multi-stakeholder user evaluation of the quality of current weather forecast products available for users in different sectors and to explore the potential for Impact-Based Forecasting (IBF) to be developed and applied for climate sensitive sectors such as disaster risk management, agriculture, and food security, water resources management, energy, and health. It should be noted that in identifying and inviting sector-specific users to participate in the workshop, we purposefully targeted those with policy making or decision making responsibilities at a national or subnational level, along with representatives of farming and fishing organizations. While this was critical for supporting interaction between National Meteorological and Hydrological Services and sector leaders and evaluating forecast provision and use at these levels, it is important to note that the decision making contexts of workshop participants differs from those whose lives and livelihoods are most precariously affected by severe weather (e.g., subsistence farmers). Hence, while participants provide valuable insight into sector-specific use of climate information, this limitation must be acknowledged. Another important aspect of the workshops was that it allowed National Meteorological Agencies to highlight their needs for resources to policy makers, as well as giving sector specific users a platform to state their forecast needs. In analyzing the findings of these workshops, we aim to address the following questions:

1) How do users of weather information in climate sensitive sectors perceive the quality of forecast products currently 
provided by National Meteorological and Hydrological Services (NMHSs)?

2) Is there a demand for impact-based approaches to weather forecasting amongst decision makers in climate sensitive sectors?

3) Which severe weather events have the greatest impact on the various sectors of activities in the different West African countries and what are the nature of these impacts?

This study is in line with recent calls advocating for a need to align climate information services to the needs of users in different sectors to enhance uptake among different user groups (Ouédraogo et al., 2018; Nkiaka et al., 2019; Carr et al., 2020). This study is particularly timely considering that the climate services community has spent much more time thinking about the quality of the information, and much less time thinking about the impact of that information on the presumed users (McNie, 2012; Vaughan et al., 2019).

\section{BACKGROUND AND CONTEXT}

Within the last decade, meteorological services have been moving away from providing phenomena-based warnings, based on specific meteorological thresholds (e.g., 10-min mean wind speed above $10 \mathrm{~m} / \mathrm{s}$ or h rainfall above $30 \mathrm{~mm}$ ), toward riskbased warnings that integrate information about the likelihood and severity of impacts arising from weather (WMO, 2015; Silvestro et al., 2019). WMO has termed this method for providing forecast information based on the potential impact of the event as "Impact-Based Forecasting." By providing a riskbased forecast, Impact-Based Forecasting (IBF) aims to enable individuals and communities to prepare appropriately while providing emergency responders crucial information to respond to threats posed by severe events (WMO, 2015).

Recent studies in developed countries indicate that, in comparison to traditional phenomena-based warnings, IBF is more consistent with how public audiences interpret the link between weather warnings and weather impacts (Taylor et al., 2019), can lead to improved understanding of forecasts (Potter et al., 2018) and may increase peoples' intention to take protective measures against severe weather (Casteel, 2016; Weyrich et al., 2018). However, the development of IBF has inherent challenges. Bringing users and producers of climate information together to link weather forecasting capability with sector-specific impacts and actions to respond to them, can require a significant resource in terms of time, money, and personnel that may not be available. At a technical level IBF also requires the processing of large datasets through data assimilation. However, recent advances in computer technology, information dissemination, use of realtime data capable of providing forecasts with greater accuracy, geographic precision and lead time offer new opportunities for enhancing IBF (Silvestro et al., 2019).

Successful implementation of IBF requires, collaboration between forecasters, and different stakeholders with expertise in geographic information systems; hydrological, crop or epidemiological modeling; social sciences and representatives of the communities at risk (WMO, 2015; Silvestro et al.,
2019). Although WMO advocates the use of IBF in DRR, the development of IBF in West Africa is still nascent.

West Africa was selected for this study because the region has experienced a number of severe weather events with devastating socio-economic impacts (Schaer and Hanonou, 2017; Salack et al., 2018; Gbode et al., 2019). In addition, climate change induced extreme weather conditions are expected to significantly affect crop production in the region (Sultan and Gaetani, 2016; Ibn Musah et al., 2018). Changing climate is also expected to cause a substantial drop in hydropower production in West Africa (Yang et al., 2018; Falchetta et al., 2019) and increase the risk of infectious disease outbreaks (Bell et al., 2018; Thomson et al., 2018).

\section{RESEARCH DESIGN AND METHODS}

Data was collected through a series of multi-stakeholder workshops organized in three West African countries (Ghana, Nigeria, and Senegal) between November 2018 and August 2019. In total, 198 participants attended four workshops bringing together forecast users from a range of climate sensitive sectors with operational weather forecasters and researchers (Table 1). In the first workshop in Ghana, only participants from institutions with offices in Accra and its environs were invited while in Senegal and Nigeria, participants from other regions outside the capital cities were invited. In Ghana, a second regional workshop was organized in Tamale in the north of the country to complement feedback from Accra. Workshops took place over 2 days in Accra, Dakar, and Abuja, and 1-day in Tamale. Workshop sessions in Ghana and Nigeria were conducted in English while French was used in Senegal. On the eve of each workshop, there was a planning meeting between the forecasters and researchers to prepare the agenda of the workshop, discuss the activities to be carried out and assign facilitators to coordinate and assist group discussion and activities. We equally visited the workshop venue to check on electronic equipment (projector and sound system), how tables will be arranged and rearranged during group activities and also check on catering.

At the beginning of each workshop, there was a brief presentation from the director of each NMHS explaining to participants the importance of climate information in socio-economic development and climate change adaptation. This highlighted the importance of bringing different user communities together to exchange ideas on ways that users think the quality of the forecast products provided by NMHSs may be enhanced. A facilitator then explained to participants the objectives of the workshops, the expected outcomes and how the workshop will be structured. This was followed by presentations from professional forecasters from NMHSs showcasing their various forecast products and services with explanations to some technical terminologies. The need to organize stakeholders' workshops bringing together forecast producers, researchers, and users of climate information to co-produce and contextualize weather forecast has been highlighted by many scientists (e.g., Buizer et al., 2016). During the workshop participant's ideas were recorded on flip charts by researchers according to the theme 
TABLE 1 | Summary of workshops participants per sector and country.

\begin{tabular}{|c|c|c|c|c|}
\hline \multirow{2}{*}{$\begin{array}{l}\text { Workshop participants } \\
\text { Sector }\end{array}$} & \multicolumn{4}{|c|}{ Country } \\
\hline & Ghana (Accra) & Ghana (Tamale) & Nigeria (Abuja) & Senegal (Dakar) \\
\hline Agriculture (crop and pastoral farming) & 12 & 11 & 24 & 19 \\
\hline Fishery & 2 & 1 & - & 8 \\
\hline Farmers & - & 5 & - & - \\
\hline Water Resources & 11 & 5 & 7 & 1 \\
\hline Disaster management & 6 & 8 & 10 & - \\
\hline Health & 2 & - & 3 & - \\
\hline Construction & - & - & 5 & - \\
\hline Media & 5 & 1 & 5 & \\
\hline Professional Forecasters & 6 & 2 & 8 & 6 \\
\hline Researchers & 6 & 4 & 9 & 4 \\
\hline Total number of participants & 50 & 37 & 73 & 38 \\
\hline
\end{tabular}

The agricultural sector is divided into two: (1) officials from the Ministry of Agriculture and related Services and (2) farmers who practice crop farming as their main livelihood activity.

under discussion. Photographs of all artifacts (flip charts) were taken as backup. The information on the flip charts was later analyzed and salient points raised during the workshop extracted.

The objectives of the workshops were to: (1) facilitate a userevaluation of the current forecast products provided by NMHSs in the target countries, (2) explore how communication of forecast products and tools of communication can be improved, and (3) explore the potential for developing IBF through identifying which weather events have the greatest impact for each climate sensitive sector. This paper focuses principally on the users' evaluation of current forecast products and exploring the potential for developing impact-based forecasting for extreme events management. It also reports on countryspecific workshop activities, such as a session dedicated to identifying key actors involved in forecast communication in Senegal where more significant investments have been made in climate communication systems (e.g., Ouédraogo et al., 2020). Another workshop session in Tamale-Ghana was dedicated to a game designed by the Red Cross Red Crescent Climate Centre called "Before the Storm" ${ }^{1}$ " to understand what motivates users of climate information to take certain decisions when forecasts indicate a high likelihood of a severe storm event.

\section{Forecast Evaluation}

To evaluate the quality of forecasts provided by National Meteorological and Hydrological Services (NMHSs), and explore how forecast communication could be improved, participants in each of the workshops were divided into sector specific groups to discuss the same questions on: (1) how forecasts are accessed and used, (2) how they are understood and trusted, (3) clarity about forecast uncertainty, and (4) how current forecast provision can be improved. This was facilitated by both a researcher and a professional forecaster from the NMHS. These smallgroup discussions were followed by a plenary session during which the same questions were deliberated upon again by all

\footnotetext{
${ }^{1}$ https://www.climatecentre.org/downloads/modules/games/Before\%20the \%20Storm.pdf
}

participants. Salient points that emerged from the plenary session were recorded on flip charts by researchers.

\section{Mapping Actors Involved in Forecast Dissemination in Senegal}

In Senegal an additional exercise was dedicated to stakeholder mapping to identify key actors involved in forecast communication in the agricultural, livestock, and fishery sectors. This exercise was aimed at identifying the key actors and institutions involved in forecast communication, particularly in rural areas. Most of the workshop participants were extension officers involved in the provision of advised to farmers, pastoralists and fishermen, including forecast information. There was a general discussion between the participants and forecasters on the administrative bottleneck reducing the quick flow of information and how this can be reduced. Participants enumerated the different institutions through which information goes through before getting to them. This was mostly seasonal forecast and advisory notes given that daily forecasts are disseminated through radio and SMS in local dialects. Participants were then asked to make proposals on how to improve on existing communication channels, and areas that they thought new communication links could be established to improve the flow of forecast information from producers to users. This information was used to produce visual map as shown on the flip charts in section Actors Involved in Forecast Dissemination (Senegal) below.

\section{Before the Storm Game (Tamale)}

Contextual factors particularly the availability of additional expertise in the project team also led the workshop facilitators to run an additional activity in the final workshop in Tamale to understand what motivates users to take certain decisions before a storm event. "Before the storm" is a participatory game designed to (a) broker a constructive dialogue without hierarchies, (b) reveal key insights about obstacles to forecast communication, and (c) elicit concrete ideas for forecast use. The objective of the game is to win the most rounds by playing 


\begin{tabular}{|c|c|c|c|c|c|c|}
\hline \multirow{6}{*}{ 葛 } & \multicolumn{3}{|c|}{ High } & & & \\
\hline & \multicolumn{3}{|c|}{ Medium } & & & \\
\hline & \multicolumn{2}{|r|}{ Low } & & & & \\
\hline & \multicolumn{2}{|c|}{ Very Low } & & & & \\
\hline & & & Very Low & Low & Medium & High \\
\hline & \multicolumn{6}{|c|}{ Impact } \\
\hline \multicolumn{2}{|c|}{ Green } & \multicolumn{5}{|c|}{ No severe weather expected } \\
\hline \multicolumn{2}{|c|}{ Yellow } & \multicolumn{5}{|c|}{$\begin{array}{l}\text { Be Aware: There is a moderate risk of severe or } \\
\text { a low risk of extreme weather occuring. Remain } \\
\text { alert and ensure you access the latest weather } \\
\text { forecast }\end{array}$} \\
\hline \multicolumn{2}{|c|}{ Amber } & \multicolumn{5}{|c|}{$\begin{array}{l}\text { Be Prepared: There is a high risk of severe or a } \\
\text { moderate risk of extreme weather occuring. } \\
\text { Remain vigilant and make sure you access the } \\
\text { latest weather forecast. Take precaution where } \\
\text { possible }\end{array}$} \\
\hline \multicolumn{2}{|c|}{ Red } & \multicolumn{5}{|c|}{$\begin{array}{l}\text { Take Action: There is a high risk of an extreme } \\
\text { weather event occuring. Remain extra vigilant and } \\
\text { ensure you access the latest weather forecast. } \\
\text { Follow orders and any advice given by the } \\
\text { authorities under all circumstances and be } \\
\text { prepared for extra ordinary measures }\end{array}$} \\
\hline
\end{tabular}

FIGURE 1 | Colour coded weather warning matrix (source: WMO, 2015).

an action card from one's hand to best "match" that round's forecast card as chosen by the game's facilitator. Through this game, workshop participants learned about weather forecasts, making appropriate and timely decisions for different lead times before disasters. After each round of the game, there was a general discussion to see if the decision taken by those taking part in the game matched the expectation of other workshop participants.

\section{Exploring Sector-Specific Weather Impacts and the Potential for IBF}

Impact-based forecasting was introduced to workshop participants based on WMO guidelines (WMO, 2015) using tools developed by the UK Met Office. Key concepts were explained to participants using examples from previous cases where IBF has been developed. A weather warning risk matrix that uses color codes to combine information about impact severity and likelihood of event happening was used to further illustrate these basic principles (Figure 1). This was used to encourage participants to think about what the impact of a severe weather event could be in terms of damages or risk to life and what kind of action can be taken in order to reduce the risk and danger to life and property. Participants were also encouraged to use their collective memory how they have dealt with previous high impact weather events in their various sectors.

Examples were used such as the impact of forecasted rainfall accumulations over $20 \mathrm{~mm}$ for the following day between 1400 UTC and midnight, on possible road closures due to flooding across the city. Using this example, participants were asked to indicate how they would react to such a forecast using the weather warning matrix in Figure 1. We highlighted that this was an exploratory exercise and participants should not expect their NMHSs to immediately start providing this kind of forecast. 
After each example, participants who were in favor or note were asked to raise their hands. The number of participants who agreed or disagreed were recorded.

In each group exercise, participants were asked to give an example of a specific weather event with significant socioeconomic impact that has recently affected their area. Using the hazard table shown in Appendix A, the event was classified according to the source of the event, the different kinds of hazard(s) caused by the event, impact severity (cost, loss of lives, and reputation) and impact probability (likelihood of event happening). Hazards were classified into primary, secondary and tertiary hazards while impacts and likelihoods are categorized as very low, low, medium and high. Facilitators, addressed specific questions from the participants. For example, the primary hazard from a tropical storm could be intense rainfall, lightning, and strong winds; secondary hazard could be flooding, disruption of telecommunication signals and the tertiary hazards could be displacement of people and loss of lives and properties. Participants first identified specific high impact weather events affecting their sector, before using their knowledge of past events, to identify what the impacts of these events could be. Each potential impact was then rated by its level of severity and its likelihood of occurrence.

\section{RESULTS AND DISCUSSION Forecast Evaluation}

During the plenary discussions following the forecast evaluation activity in each country, more than $90 \%$ of workshop participants across the three countries expressed the opinion that the quality of forecast products provided by their NMHSs has substantially improved in recent years. This finding is consistent with prior work in Ghana in which workers in the public sector reported a perceived improvement in the quality of forecast delivered by the Ghana Meteorological Agency (Anaman et al., 2017). Another CIS evaluation exercise in Senegal has also revealed that more than two million farmers now receive seasonal forecast information as a result of enhanced quality of forecast products characterized by region-specific and timely dissemination of seasonal rainfall forecasts that suit the needs of farmers ${ }^{2}$ This indicates that the provision of CIS is improving with different user communities becoming increasingly aware of the NMHSs' responsibilities and the forecast products they provide. A summary of the outcome of forecast evaluation is given in Table 2.

\section{Forecast Accessibility}

Participants from capital cities (i.e., Accra, Dakar, and Abuja) primarily accessed weather forecasts through television and print media. Participants from other regions, such as Tamale in Ghana, Saint Louis in Senegal, and Kano in Nigeria indicated that, they mostly access forecasts through community radio and short message service (SMS). This is consistent with earlier studies suggesting that radio is the preferred means of receiving weather

\footnotetext{
${ }^{2}$ https://ccafs.cgiar.org/bigfacts/\#theme=evidence- of- success\&subtheme= services\&casestudy $=$ servicesCs 3
}

forecasts amongst rural farming communities (Nkiaka et al., 2019). In Senegal, access to weather forecast by means of SMS, WhatsApp group messages and voice call (in local language) is very common particularly among the farming and fishing communities as revealed by participants during the workshop and in other studies (e.g., Ouédraogo, 2018; Diouf et al., 2019; Ouédraogo et al., 2020). In Ghana and Nigeria, agriculture sector participants reported that SMS messages are being received by a selected few members of farming organizations involved in CIS projects. For example, one farmer remarked during the workshop in Tamale that: "only few members of their community involve in CIS projects do receive forecast through SMS and once the project ends, they cannot longer access the forecasts through this means. For this reason, members of our community do not rely on weather forecasts to make farming decisions because we are not sure when the next CIS project will come and if the same farming group will be selected to take part in the project." This prevents continuous uptake and use of climate information by members of such communities. Our workshop findings highlight that intermittent services linked to shortlived projects are detrimental to the uptake and adoption of climate services among farming communities (see also Singh et al., 2016). This underscores the importance of mainstreaming project sustainability at the early stages of project design to ensure that CIS are provided to users without interruption at the end of the pilot project.

In both Ghana and Nigeria, participants from the agriculture and food security sector expressed dissatisfaction with their inability to access seasonal forecasts and updates from NMHSs. Other studies in the region have also identified the lack of access to seasonal forecasts (and sub-seasonal updates) to be a major constraint to climate change adaptation for farming communities (Otitoju and Enete, 2016; Ifeanyi-Obi et al., 2017; Guodaar and Asante, 2018; Naab et al., 2019). However, this was not the case in Senegal, where evidence from workshop participants suggested that "Agence Nationale de l'Aviation Civile et de la Météorologie" (ANACIM) has developed a successful approach for disseminating forecasts to different user communities. The success of ANACIM in developing a better strategy to disseminate climate information may be attributed to experience in managing climate related risks following the Sahel droughts and significant investment from the international community to build the country's resilience to climate risks (Carr et al., 2016; Diouf et al., 2019; Ouédraogo et al., 2020).

Participants from the DRR, water management and hydropower sectors in Ghana and Nigeria indicated that their access to CIS is by formal institutional requests to NMHS. However, they also highlighted that when forecasts for high impact weather events such as storms and strong winds are issued, Ghana Meteorological Agency (GMet) and Nigeria Meteorological Agency (NiMet) send forecasts and advisories to their institutions using formal administrative channels, with follow-up calls to ensure that the forecasts have been received. Participants from the water management sector mentioned that when forecasts for high impact events are issued, dam managers and DRR organizations work together to inform communities living downstream of storage dams about safety measures to take 
TABLE 2 | Summary of forecast evaluation.

\begin{tabular}{|c|c|c|c|c|}
\hline \multirow{2}{*}{$\begin{array}{l}\text { Forecast theme } \\
\text { evaluated }\end{array}$} & \multicolumn{4}{|c|}{ Participants views } \\
\hline & Ghana- Accra & Ghana-Tamale & Nigeria & Senegal \\
\hline $\begin{array}{l}\text { General forecast } \\
\text { quality }\end{array}$ & Significant improvements & Significant improvements & Significant improvements & Significant improvements \\
\hline Mode of accessibility & $\begin{array}{l}\text { TV, print, radio, and institutional } \\
\text { requests (sector specific) }\end{array}$ & $\begin{array}{l}\text { TV, Radio, SMS (farmers } \\
\text { preference but not available) }\end{array}$ & $\begin{array}{l}\text { TV, print, radio and institution } \\
\text { requests (sector specific) }\end{array}$ & $\begin{array}{l}\text { TV, Radio, SMS, WhatsApp, } \\
\text { voice call (in local language) }\end{array}$ \\
\hline Uses & Uses vary by sector & Uses vary by sector & Uses vary by sector & Uses vary by sector \\
\hline Trust & $\begin{array}{l}\text { Lack of trust due to forecast } \\
\text { being issued late, lack of } \\
\text { updates, and repeated } \\
\text { incidences of false } \\
\text { alarms/misses }\end{array}$ & $\begin{array}{l}\text { Lack of trust due to forecast } \\
\text { being issued late, lack of } \\
\text { updates, and repeated } \\
\text { incidences of false } \\
\text { alarms/misses }\end{array}$ & $\begin{array}{l}\text { Lack of trust due to forecast } \\
\text { being issued late, lack of } \\
\text { updates, and repeated } \\
\text { incidences of false } \\
\text { alarms/misses }\end{array}$ & $\begin{array}{l}\text { Lack of trust due to forecast } \\
\text { being issued late, lack of } \\
\text { updates, and repeated } \\
\text { incidences of false } \\
\text { alarms/misses }\end{array}$ \\
\hline $\begin{array}{l}\text { Uncertainty } \\
\text { /Understanding } \\
\text { /Clarity }\end{array}$ & $\begin{array}{l}\text { Multiple challenges such as } \\
\text { coarse spatial resolution, format } \\
\text { and content, lack of advisory } \\
\text { notes }\end{array}$ & $\begin{array}{l}\text { Multiple challenges such as } \\
\text { coarse spatial resolution, format } \\
\text { and content, lack of advisory } \\
\text { notes }\end{array}$ & $\begin{array}{l}\text { Multiple challenges such as } \\
\text { coarse spatial resolution, format } \\
\text { and content, lack of advisory } \\
\text { notes }\end{array}$ & $\begin{array}{l}\text { Multiple challenges such as } \\
\text { coarse spatial resolution, format } \\
\text { and content, lack of advisory } \\
\text { notes }\end{array}$ \\
\hline
\end{tabular}

depending on the duration and volume of water to be released from the dams. This demonstrates the existence of close working relationships between NMHSs and users in key sectors, which could support the implementation of IBF by NMHSs.

\section{Forecast Use}

The ways the forecasts are used varies from sector-to-sector reflecting the different types of decisions made in each and this was consistent across the four workshops. Participants in the agricultural sector reported that they use seasonal forecasts to plan for their farming activities and make decisions about crop variety and planting dates. Those in the water management and hydropower sector use forecasts to plan for dam management operations. Participants from the DRR sector highlighted that seasonal forecasts are mostly used for planning for relief operations while weather forecasts are used for operation decisions such as training of volunteers and pre-positioning of relief materials. Other participants from semi-arid regions of Senegal and northern Nigeria indicated that they use daily forecasts to make decisions regarding suitable clothing.

\section{Trust in Forecast}

In spite perceiving improvement in the quality of forecast products provided by the NMHSs, the majority of workshop participants in each country noted that there was still a lack of trust in the forecast provided. This was attributed by many participants to the view that forecasts, particularly those for high impact events, are often issued too late for any meaningful actions to be taken. The fact that forecasts are not always regularly updated (e.g., notifications not being issued to signal that warnings are no longer in place), was also highlighted as a barrier to trust. False alarm/misses were also highlighted as a critical factor contributing to a lack of trust in forecast. This finding is in line with research in developed countries suggesting false alarm or misses erode public trust in weather warnings and when uncertainties are not adequately communicated (LeClerc and Joslyn, 2015).

\section{Uncertainty and Understanding}

Clarity about forecast uncertainty was mostly attributed to the fact that forecasts most often do not cover areas of interest due to a lack of adequate spatial resolution. Poor understanding of forecasts was partly attributed to the fact that the content and format are too technical and not clearly explained. This issue has been identified to be a key barrier to the uptake and adoption of CIS in SSA (Ochieng et al., 2017). Participants highlighted that the time slots allocated to forecast presentation on TV and radio are usually very short and does not always provide detailed spatial coverage and advice on what to do by members of the public.

\section{How Can Current Provision Be Improved?}

Various ways of improving forecast uptake were suggested by participants. For example, participants suggested that forecasts (daily and seasonal) should carry advisory notes both for members of the public and for specific sectors especially the farming and pastoral sub-sectors where most users cannot interpret forecasts. For this to be successful, participants recognized that providers of CIS will need to work in collaboration with users from different sectors to contextualize and co-produce forecast products with advisory notes suitable to the needs of specific users. A similar approach is currently used in Kenya to facilitate bottom-up community-led disaster risk management and food security coordination (Nurye, 2016). Other studies have also reported that a strong collaboration between producers and users of climate and weather information is critical to enhance the uptake and adoption of CIS in SSA (Amegnaglo et al., 2017; Hansen et al., 2019). Of course, while a strong collaboration between users and producers of CIS is encouraged, enabling these collaborations to take place is a challenge in CIS development, owing to constraints in time, personnel availability and financial resources. Successful collaboration also requires that careful consideration be given to 
procedures to effectively assess users and their needs, identify and overcome barriers to the use of CIS, scale-up CIS, and address the challenge of dealing with the rapidly evolving knowledge (Carr et al., 2020). Participants stressed the need for NMHSs to provide adequate training on CIS to agriculture extension officers given their close working relationship with the farming and pastoralist communities. According to the participants, this training will enhance their skills on how to interpret forecast products. Adopting more suitable communication channels were equally suggested as ways to improve forecast delivery and uptake. This is in addition to points mentioned earlier about improving spatial and temporal resolution and regularly updating forecasts. Approaches identified for enhancing forecast accessibility include: allocating sufficient time on TV for forecast presentation, translating seasonal forecast products into local languages and making it accessible directly to users by using social media platforms such as WhatsApp groups. Across all the sectors evaluated, participants emphasized that the use of simple, easy to understand language, as opposed to unexplained technical language will facilitate successful uptake and implementation of IBF in West Africa.

\section{Actors Involved in Forecast Dissemination (Senegal)}

In Senegal, a stakeholder mapping analysis was undertaken to identify key actors involved in forecast communication. This allowed identification of existing and missing links in information flow within sectors (Figure 2). In Figure 2, the left panel shows that the seasonal forecast bulletins prepared by "Agence Nationale de l'Aviation Civile et de la Météorologie" (ANACIM) are not directly communicated to the farmers and also a lack of communication between ANACIM and local administrative authorities (absence of a communication link). The right panel shows that there is a lack of communication between ANACIM, the pastoralist community and other decentralized services (absence of communication link). The two figures were produced by stakeholders from crop farming and pastoral sub-sectors. The exercise highlighted the need for ANACIM to establish direct links with Local Councils, administrative authorities, and local multidisciplinary working groups, given their proximity to farming communities. There was also some expectation for ANACIM to establish stronger links with farmers, pastoralists, and fishing communities so that forecasts and advisories can be provided directly to them, with intermediaries explaining those aspects of the forecast that are unclear.

\section{Outcome of Before the "Storm Game" (Tamale)}

Workshop participants found this game to be very engaging and speed up the learning process among participants. Participants across different sectors gave examples of decisions they would take in real life given predicted weather conditions. Most of these decisions resonated strongly between selected game players and the whole workshop participants working within similar sectors. However, the participants regretted that the time allocated for the exercise was not enough to raise other specific issues that may hinder their decision-making processes.

A remarkable outcome of the district-level workshop organized in Tamale is that it was possible to get the voices of the farmers which was not possible for workshops organized in urban centers such as Accra, Abuja, and Dakar. As highlighted earlier, one of the farmers expressed the frustration that the use of climate information in decision making in their community is low because of intermittent forecast provision. Another significant outcome was that while the interest of urbanites in CIS was more focused toward disaster prevention particularly flooding, those from rural areas were more interested in the onset and cessation dates for rainfall which is more related to agricultural drought management. However, there was no significant difference in the type of weather events identified by urbanites and people living in rural areas.

\section{Exploring the Potential for Impact-Based Forecasting in West Africa}

Amongst participants in all four workshops, there was high demand for the development of weather warnings that are linked to the consequences of severe weather events rather than the exceedance of meteorological thresholds alone, and for this to linked to recommended actions. A strong interest was expressed in receiving daily forecasts with color-coded warnings to aid in better understanding the risk posed by weather. Together, this indicates strong support for risk-based approaches to warnings and that the development and application of IBF could increase the usefulness and uptake of weather forecasts in West Africa. The new generation of high resolution forecast models such as the UKMO $4 \mathrm{~km}$ convection permitting simulation model with improved skill for capturing precipitation distribution at both daily and sub-daily time-scales over the West Africa can greatly enhance IBF implementation in the region (Berthou et al., 2019; Kendon et al., 2019).

Table 3 provides a summary of high impact weather events identified during the workshops. Tropical storms were a challenge for virtually all sectors and countries, while other events had a more restricted sectoral or regional impact. Common weather events identified included tropical storms, drought, heat waves and dust storms/strong winds. These were identified as common high impact events significant socio-economic impact for most sectors. In most cases, the events identified were consistent with existing work indicating that they are increasing in frequency and intensity. Recent studies focussing on West Africa, for instance reported an increasing trend in heat waves (Moron et al., 2016; Ceccherini et al., 2017), child mortality attributed to dust storms (Foreman, 2018; Adhvaryu et al., 2019) and high intensity rainfall caused by storm events (Berthou et al., 2019). The results of this exercise suggested that amongst sectors represented in the workshops, tropical storms, droughts, and heat waves were rated as having a higher level of impact than dust storms or strong winds.

\section{Tropical Storms}

Most of the impacts identified as resulting from tropical storms were caused by floods ranging from the displacement of 


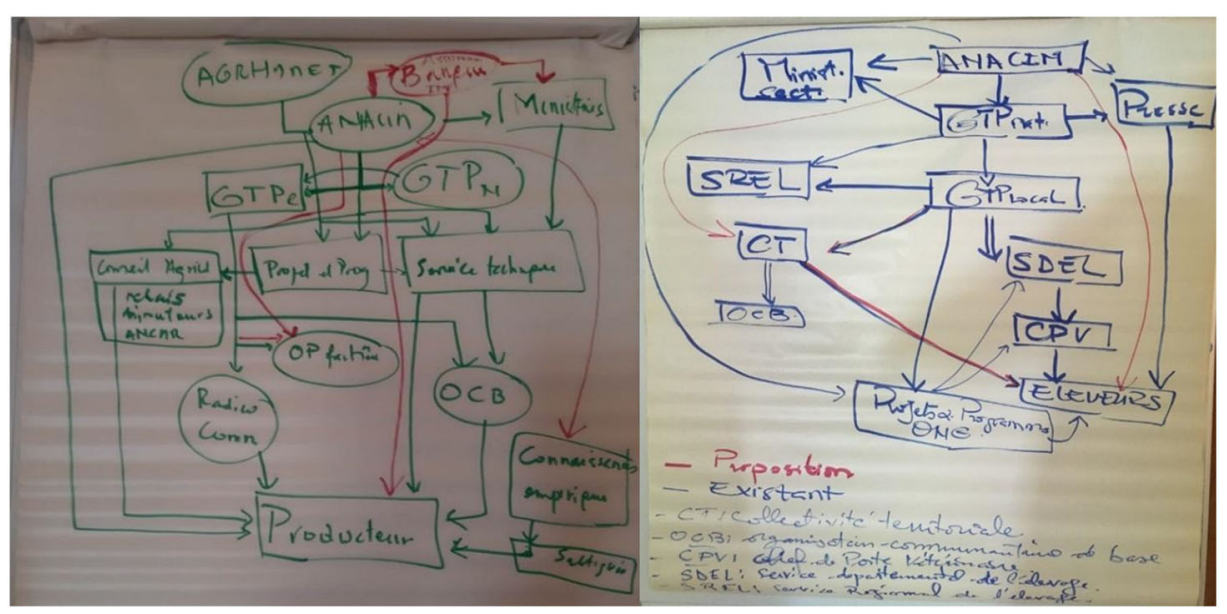

FIGURE 2 | Example of organization chart showing existing and missing links (red) for the agricultural sector (left) and livestock sector (right) produced by stakeholders in Senegal.

TABLE 3 | Summary of high impact weather events, impact severity, and likelihood.

\begin{tabular}{|c|c|c|c|c|}
\hline $\begin{array}{l}\text { Weather } \\
\text { event }\end{array}$ & Sectors impacted & $\begin{array}{l}\text { Impact } \\
\text { severity }\end{array}$ & Likelihood & Country \\
\hline $\begin{array}{l}\text { Tropical } \\
\text { storms }\end{array}$ & $\begin{array}{l}\text { agriculture (crop cultivation, livestock, and fishery), water resources and hydropower, } \\
\text { disaster management, construction }\end{array}$ & High & High & $\begin{array}{l}\text { Ghana, Nigeria, } \\
\text { and Senegal }\end{array}$ \\
\hline Drought & Agriculture, environment, health & High & High & Nigeria, Senegal \\
\hline Dust storms & Health, livestock, construction & Medium & High & Nigeria, Senegal \\
\hline Strong winds & Agriculture, fishery, construction, disaster management, & Medium & Low & $\begin{array}{l}\text { Nigeria, Ghana, } \\
\text { and Senegal }\end{array}$ \\
\hline Heat waves & Health, livestock & High & High & $\begin{array}{l}\text { Ghana, Nigeria, } \\
\text { and Senegal }\end{array}$ \\
\hline
\end{tabular}

TABLE 4 | Key recommendations from the workshops.

\section{Ensure sustainability of CIS projects}

Improvement of spatial and temporal resolution of forecasts

Provide forecasts with advisory notes

Develop and implement IBF for tropical storms, droughts, heatwaves, and dust storms

Enhance the capacity of NMHSs to incorporate IBF in their work

Regularly updating forecasts on television

Allocating sufficient time for forecast broadcast on TV

people, loss of lives, livelihoods, the submersion of hydropower stations, the disruption to power production and slow down of economic activities across most sectors. Flooding could also cause disruption to urban water drainage and treatment, triggering water-borne diseases such as cholera and leading to the loss of life. Flooding caused by a tropical storm can also destroy crops directly or through the increased incidence of pests and cause death of livestock which are all threats to food security. It can also reduce dam storage capacity through sedimentation and dam failure leading to loss of lives and disruption of services. Landslides resulting from a tropical storm usually lead to the disruption of transport activities with negative impact on economic activities. Many studies have reported about the impact of floods in West Africa (Schaer and Hanonou, 2017; Salack et al., 2018; Gbode et al., 2019; Ansah et al., 2020). Participants also highlighted that tropical storms via increased wave conditions have significant negative impact in the fishing sector including the destruction of small-size fishing boats and loss of lives, destruction of fishing infrastructure in coastal areas and disruption of fishing activities.

\section{Drought}

Drought was equally identified as an event with many impacts including the destruction of crops, increased incidence of crop pests, loss of pasture for livestock and dry-up of water points for livestock which usually cause starvation, dehydration and death of livestock resulting in food insecurity and loss of livelihood for the farming and pastoralist communities. Drought is also a major cause of land degradation and loss of soil fertility and biodiversity which are triggers of famine and food insecurity in West Africa (Zakari et al., 2014). It is also a major cause of farmer-pastoralist conflicts as reported in other studies in West Africa (e.g., Okpara et al., 2015). Additional impacts from drought include low water levels in hydropower and urban water supply dams as a result of 
reduced river flows and increased evaporation. This could lead to power rationing (load shedding) which has a significant negative impact on the economic productivity in West Africa (Diboma and Tatietse, 2013).

Although climate change is expected to increase the frequency and intensity of drought events around the world (Field et al., 2012), drought remains a relatively understudied topic (Padma, 2019). The new generation NOAA operational satellite JPSS-1 capable of early detection of drought, accurately monitor it at high spatial resolution, provide drought intensity, duration, and predict agricultural losses 2 months ahead of crop harvest offer new opportunities for monitoring the impact of drought in West Africa (Kogan et al., 2019). Such advances in earth observation represent a significant step in the implementation of IBF in the region.

\section{Heat Waves}

Heat waves were identified as a major high impact weather event with significant impact on human health particularly in Nigeria and Senegal. Participants stated that heat waves frequently lead to outbreak of deadly diseases such as meningitis which is in line with what has been reported in other studies in the region (Agier et al., 2013; Koutangni et al., 2019). Heat waves have been reported to have significant impact on mortality and morbidity in Africa with the urban heat island effect increasing the health risk for people living in cities (Zaitchik, 2017). The impact of heat waves on the livestock sector include (1) the massive death of livestock leading to economic losses and (2) increase transhumance activity which usually triggers farmer-pastoralist conflicts. Heat waves were also identified as a major trigger of wildfire which may lead to substantial loss of vegetation and destruction of terrestrial ecosystems in the region (Pereira et al., 2020).

\section{Dust Storms}

It was highlighted during the workshops in Nigeria and Senegal that dust storms frequently cause traffic accidents as a result of reduced visibility. Participants also highlighted their significant health impact including the outbreak of diseases such as meningitis which is in line with results of previous studies in the region (Diokhane et al., 2016). It also causes disruption of economic activities particularly in the construction sector leading to a drop in economic productivity as highlighted by participants in Nigeria. Hence, providing adequate forecast for dust storms may be regarded as an integral package of IBF products in West Africa.

\section{Strong Winds}

Strong winds were equally identified as another weather event with significant economic and human impact especially for the construction sector in Nigeria and the fishing sector in Senegal. Participants from the construction sector in Nigeria stated that strong winds are the primary cause of accidents on construction sites as strong winds destroy power cranes, thus disrupting construction activities. This is also in line with results published in other studies that have equally reported an increase in wind hazards in Nigeria with substantial direct and indirect impacts on socio-economic activities (Adelekan, 2012). This shows that there is a recognized need to develop IBF for strong winds in both Nigeria and Senegal. A summary of key recommendations from the workshops is provided in Table 4.

\section{CONCLUSION AND POLICY RECOMMENDATIONS}

Our findings show that forecast accessibility, forecast use, trust in forecast, forecast uncertainty and understanding were key concerns raised by participants across the target countries and sectors in West Africa. Access to weather forecast by means of SMS messages was more developed among the farming and fishing communities in Senegal than in Ghana and Nigeria where accessing forecast through SMS messages was only possible through short-lived projects. To enhance the uptake and adoption of CIS, there is a strong need to mainstream CIS sustainability as a key deliverable in CIS projects to ensure that the provision of weather information to users is not disrupted when the project ends. Participants recommended that further improvement of the spatial and temporal resolution of forecasts, co-producing forecast with different user groups, regularly updating forecasts, providing forecasts accompanied with advisory notes, and allocating sufficient time for forecast broadcast will improve the uptake of CIS.

Given the substantial socio-economic impact of tropical storms, droughts, heat waves, dust storms/strong winds, forecasters need to prioritize the development and implementation of impact-based forecasting for such events. This reinforces the need to implement IBF in West Africa. For this to be successful, there is an urgent need for governments in the region to enhance the capacity of NMHSs so that they can incorporate IBF as a routine forecast activity in their work plan. This could be achieved by first putting in place a National Framework for Climate Services (NFCS). The government could also organize workshops with different sectors to contextualize climate information and advisory notes for each sector, how to enhance forecast dissemination and also identify barriers to the uptake to climate information. Moreover, the National Meteorological and Hydrological Services need to work in partnership with other institutions across the target countries to identify the most vulnerable provinces/states/regions and villages which are usually most affected by such high impact events in order to develop additional plans to be put in place to reduce their vulnerability.

\section{DATA AVAILABILITY STATEMENT}

The datasets generated for this study can be found in online repositories. The names of the repository/repositories and accession number(s) can be found in the article/Supplementary Material. 


\section{AUTHOR CONTRIBUTIONS}

EN analyzed all the data collected from the four workshops and wrote the first draft of the paper. $\mathrm{ATa}, \mathrm{AD}$, and PA-A commented on the methodology and study design. All authors participated and facilitated at least one workshop session in the capacity of either a project researcher or a professional forecaster and provided contributions to the final manuscript. From the fifth author, names appear in alphabetical order.

\section{FUNDING}

This work was supported by UK Research and Innovation as part of the Global Challenges Research

\section{REFERENCES}

Adelekan, I. O. (2012). Vulnerability to wind hazards in the traditional city of Ibadan, Nigeria. Environ. Urban. 24, 597-617. doi: 10.1177/0956247812454247 Adhvaryu, A., Bharadwaj, P., Fenske, J., Nyshadham, A., and Stanley, R. (2019). Dust and Death: Evidence From the West African Harmattan. National Bureau of Economic Research Working Paper No. 25937. Oxford: Centre for the study of African Economies, University of Oxford, UK.

Agier, L., Deroubaix, A., Martiny, N., Yaka, P., Djibo, A., and Broutin, H. (2013). Seasonality of meningitis in Africa and climate forcing: aerosols stand out. J. $R$ Soc. Interface 10:20120814. doi: 10.1098/rsif.2012.0814

Allis, E., Hewitt, D. C., Ndiaye, O., Hama, A. M., Fisher, M. A., Bucher, A., et al. (2019). The future of climate services. 591 World Meteorol. Org Bull. 68.

Amegnaglo, C. J., Anaman, K. A., Mensah-Bonsu, A., Onumah, E. E., and Gero, F. A. (2017). Contingent valuation study of the benefits of seasonal climate forecasts for maize farmers in the republic of Benin, West Africa. Clim. Serv. 6, 1-11. doi: 10.1016/j.cliser.2017.06.007

Anaman, K. A., Quaye, R., and Amankwah, E. (2017). Evaluation of public weather services by users in the formal services sector in Accra, Ghana. Modern Econ. 8, 921-945. doi: 10.4236/me.2017.87065

Ansah, S. O., Ahiataku, M. A., Yorke, C. K., Otu-Larbi, F., Yahaya, B., Lamptey, P. N. L., et al. (2020). Meteorological analysis of floods in ghana. Adv. Meteorol. 2020:4230627. doi: 10.1155/2020/4230627

Azzarri, C., and Signorelli, S. (2020). Climate and poverty in Africa South of the Sahara. World Dev. 125:104691. doi: 10.1016/j.worlddev.2019.104691

Bell, J. E., Brown, C. L., Conlon, K., Herring, S., Kunkel, K. E., Lawrimore, J., et al. (2018). Changes in extreme events and the potential impacts on human health. J. Air Waste Manag. Assoc. 68, 265-287. doi: 10.1080/10962247.2017.1401017

Berthou, S., Rowell, D. P., Kendon, E. J., Roberts, M. J., Stratton, R. A., Crook, J. A., et al. (2019). Improved climatological precipitation characteristics over West Africa at convection-permitting scales. Clim. Dyn. 53, 1991-2011. doi: $10.1007 /$ s00382-019-04759-4

Brasseur, G. P., and Gallardo, L. (2016). Climate services: lessons learned and future prospects. Earth's Future 4, 79-89 doi: 10.1002/2015EF000338

Buizer, J., Jacobs, K., and Cash, D. (2016). Making short-term climate forecasts useful: linking science and action. Proc. Natl. Acad. Sci. U.S.A. 113, 4597-4602. doi: $10.1073 /$ pnas. 0900518107

Carr, E.R., Fleming, G., and Kalala, T. (2016). Understanding women's needs for weather and climate information in agrarian settings: the case of Ngetou Maleck, Senegal. Weather Clim. Soc. 8, 247-264. doi: 10.1175/WCAS-D-15-0075.1

Carr, E. R., Goble, R., Rosko, H. M., Vaughan, C., and Hansen, J. (2020). Identifying climate information services users and their needs in SubSaharan Africa: a review and learning agenda. Clim. Dev. 12, 23-41. doi: 10.1080/17565529.2019.1596061

Casteel, M. A. (2016). Communicating increased risk: an empirical investigation of the national weather service's impact-based warnings. Weather Clim. Soc. 8, 219-232. doi: 10.1175/WCAS-D-15-0044.1
Fund, Africa SWIFT programme-grant number NE/P021077/1.

\section{ACKNOWLEDGMENTS}

The authors express their sincere gratitude to all participants who took part in the workshops that led to the writing of this paper.

\section{SUPPLEMENTARY MATERIAL}

The Supplementary Material for this article can be found online at: https://www.frontiersin.org/articles/10.3389/fclim. 2020.565500/full\#supplementary-material
Ceccherini, G., Russo, S., Ameztoy, I., Marchese, A. F., and Carmona-Moreno, C. (2017). Heat waves in Africa 1981-2015, observations and reanalysis. Nat. Hazards Earth Syst. Sci. 17, 115-125. doi: 10.5194/nhess-17-115-2017

Coulibaly, Y. J., Kundhlande, G., Amosi, N., Tall, A., Kaur, H., and Hansen, J. (2015). What Climate Services do Farmers and Pastoralists Need in Tanzania? Baseline Study for the GFCS Adaptation Program in Africa. CCAFS Working Paper no. 110. CGIAR Research Program on Climate Change, Agriculture and Food Security (CCAFS). Copenhagen. Available online at: www.ccafs.cgiar.org (accessed August 10, 2020).

Daly, M. E., West, J. J., and Yanda, P. Z. (2016). Establishing a Baseline for Monitoring and Evaluating User Satisfaction With Climate Services in Tanzania. CICERO Center for International Climate and Environmental Research-Oslo. Available online at: https://www.cicero.oslo.no/en/publications/internal/2829 (accessed July 21, 2020).

Diboma, B., and Tatietse, T. T. (2013). Power interruption costs to industries in cameroon. Energy Policy 62, 582-592. doi: 10.1016/j.enpol.2013.07.014

Diokhane, A. M., Jenkins, G. S., Manga, N., Drame, M. S., and Mbodji, B. (2016). Linkages between observed, modeled Saharan dust loading and meningitis in Senegal during 2012 and 2013. Int. J. Biometeorol. 60, 557-575. doi: 10.1007/s00484-015-1051-5

Diouf, N. S., Ouedraogo, I., Zougmoré, R. B., Ouedraogo, M., Partey, S. T., and Gumucio, T. (2019). Factors influencing gendered access to climate information services for farming in Senegal. Gend. Technol. Dev. 23, 93-110. doi: 10.1080/09718524.2019.1649790

Drost, R., Casteel, M., Libarkin, J., Thomas, S. and Meister, M. (2016). Severe weather warning communication: factors impacting audience attention and retention of information during tornado warnings. Weather Climate Society 8, 361-372. doi: 10.1175/WCAS-D-15-0035.1

Falchetta, G., Gernaat, D., Hunt, J., and Sterl, S. (2019). Hydropower dependency and climate change in sub-Saharan Africa: a nexus framework and evidencebased review. J. Clean. Prod. 231, 1399-1417. doi: 10.1016/j.jclepro.2019.05.263

Field, C. B., Barros, V., Stocker, T. F., and Dahe, Q. (2012). Managing the risks of Extreme Events and Disasters to Advance Climate Change Adaptation: Special Report of the Intergovernmental Panel on Climate Change. Cambridge: Cambridge University Press.

Foreman, T. (2018). The Effect of Dust Storms on Child Health in West Africa. Columbia University: CDEP-CGEG Working Paper.

Gbode, I. E., Adeyeri, O. E., Menang, K. P., Intsiful, J. D., Ajayi, V. O., Omotosho, J. A., et al. (2019). Observed changes in climate extremes in Nigeria. Meteorol. Appl. 26, 642-654. doi: 10.1002/met.1791

Guodaar, L., and Asante, F. (2018). Using a factor analysis to understand climate adaptation barriers impeding smallholder tomato farmers in the Offinso North District, Ghana. Cogent Food Agric. 4:1504507. doi: 10.1080/23311932.2018.1504507

Hansen, J. W., Vaughan, C., Kagabo, D. M., Dinku, T., Carr, E. R., Körner, J., et al. (2019). Climate services can support african farmers' context-specific adaptation needs at scale. Front. Sustain. Food Syst. 3:21. doi: $10.3389 /$ fsufs. 2019.00021 
Hewitt, C., Mason, S., and Walland, D. (2012). The global framework for climate services. Nat. Clim. Change 2, 831-832. doi: 10.1038/nclimate 1745

Ibn Musah, A. A., Du, J., Bilaliib Udimal, T., and Abubakari Sadick, M. (2018). The nexus of weather extremes to agriculture production indexes and the future risk in ghana. Climate 6:86. doi: 10.3390/cli6040086

Ifeanyi-Obi, C., Togun, A., Lamboll, R., Adesope, O., and Arokoyu, S. (2017). Challenges faced by cocoyam farmers in adapting to climate change in Southeast Nigeria. Clim. Risk Manag. 17, 155-164. doi: $10.1016 /$ j.crm.2017.04.002

ITU (2013). International Telecommunication Union, Technical Report on Telecommunications and Disaster Mitigation. Available online at: https://www. itu.int/en/ITU-T/focusgroups/drnrr/Documents/Technical_report-2013-06. pdf (accessed April 14, 2020).

Jones, L., Dougill, A., Jones, R. G., Steynor, A., Watkiss, P., Kane, C., et al. (2015). Ensuring climate information guides long-term development. Nat. Clim. Change 5, 812-814. doi: 10.1038/nclimate2701

Kendon, E. J., Stratton, R. A., Tucker, S., Marsham, J. H., Berthou, S., Rowell, D. P., et al. (2019). Enhanced future changes in wet and dry extremes over Africa at convection-permitting scale. Nat. Commun. 10:1794. doi: 10.1038/s41467-019-09776-9

Kogan, F., Guo, W., and Yang, W. (2019). Drought and food security prediction from NOAA new generation of operational satellites. Geomatics Nat. Hazards Risk 10, 651-666. doi: 10.1080/19475705.2018.1541257

Koutangni, T., Crépey, P., Woringer, M., Porgho, S., Bicaba, B., Tall, H., et al. (2019). Compartmental models for seasonal hyperendemic bacterial meningitis in the African meningitis belt. Epidemiol. Infect. 147, 1-11. doi: $10.1017 /$ S0950268818002625

Lamond, J., Adekola, O., Adelekan, I., Eze, B., and Ujoh, F. (2019). Information for adaptation and response to flooding, multi-stakeholder perspectives in Nigeria. Climate 7:46. doi: 10.3390/cli7040046

LeClerc, J., and Joslyn, S. (2015). The cry wolf effect and weatherrelated decision making. Risk Anal. 35, 385-395. doi: 10.1111/risa. 12336

Machingura, F., Nyamwanza, A., Hulme, D., and Stuart, E. (2018). Climate information services, integrated knowledge systems and the 2030 agenda for sustainable development. Sustain. Earth 1:1. doi: 10.1186/s42055-018-0003-4

McKune, S., Poulsen, L., Russo, S., Devereux, T., Faas, S., McOmber, C., et al. (2018). Reaching the end goal: do interventions to improve climate information services lead to greater food security? Clim. Risk Manag. 22, 22-41. doi: $10.1016 /$ j.crm.2018.08.002

McNie, E. C. (2012). Delivering climate services: organizational strategies and approaches for producing useful climate-science information. Weather Clim. Soc. 5, 14-26. doi: 10.1175/WCAS-D-11-00034.1

Moron, V., Oueslati, B., Pohl, B., Rome, S., and Janicot, S. (2016). Trends of mean temperatures and warm extremes in northern tropical Africa (1961-2014) from observed and PPCA-reconstructed time series. J. Geophys. Res. Atmos. 121, 5298-5319. doi: 10.1002/2015JD024303

Mysiak, J., Castellari, S., Kurnik, B., Swart, R., Pringle, P., Schwarze, R., et al. (2018). Brief communication: strengthening coherence between climate change adaptation and disaster risk reduction. Nat. Hazards Earth Syst. Sci. 18, 3137-3143. doi: 10.5194/nhess-18-31372018

Naab, F. Z., Abubakari, Z., and Ahmed, A. (2019). The role of climate services in agricultural productivity in ghana: the perspectives of farmers and institutions. Clim. Serv. 13, 24-32. doi: 10.1016/j.cliser.2019.01.007

Nkiaka, E., Taylor, A., Dougill, A. J., Antwi-Agyei, P., Fournier, N., Bosire, E. N., et al. (2019). Identifying user needs for weather and climate services to enhance resilience to climate shocks in sub-Saharan Africa. Environ. Res. Lett. 14:123003. doi: 10.1088/1748-9326/ab4dfe

Nurye, A. A. (2016). Blending science and community voices for multi-scale disaster risk reduction and climate resilience: a participatory scenario planning approach. Ethiopian J. Environ. Stud. Manag. 9, 904-919. doi: 10.20944/preprints201608.0105.v1

Ochieng, R., Recha, C., and Bebe, B. O. (2017). Enabling conditions for improved use of seasonal climate forecast in arid and semi-arid Baringo county-Kenya. Open Access Library J. 4, 1-15. doi: 10.4236/oalib.1103826
Okpara, U. T., Stringer, L. C., Dougill, A. J. and Bila, M. D. (2015). Conflicts about water in Lake chad: are environmental, vulnerability and security issues linked? Prog. Dev. Stud. 15, 308-325. doi: 10.1177/1464993415592738

Otitoju, M. A., and Enete, A. A. (2016). Climate change adaptation: uncovering constraints to the use of adaptation strategies among food crop farmers in South-west, Nigeria using principal component analysis (PCA). Cogent Food Agric. 2:1178692. doi: 10.1080/23311932.2016.1178692

Ouédraogo, I. (2018). Forewarned is Forearmed: How Climate Information Services are Saving the Lives and Livelihoods of Senegalese Fisherfolk. The Food and Agriculture Organization (FAO). Rome: CGIAR Research Program on Climate Change; Agriculture and Food Security (CCAFS). Available online at: https:// hdl.handle.net/10568/100125 (accessed April 27, 2020).

Ouédraogo, I., Diouf, N. S., Zougmoré, R., Ndiaye, O., and Touré, A. A. (2020). Options de Modèles d'Affaires pour Assurer la Durabilité de l'Utilisation des Services d'Information Climatique au Sénégal. Programme de Recherche du CGIAR sur le Changement Climatique, l'Agriculture et la Sécurité Alimentaire (CCAFS). Pays Bas: Wageningen University \& Research.

Ouédraogo, M., Barry, S., Zougmoré, R. B., Partey, S. T., Somé, L., and Baki, G. (2018). Farmers' willingness to pay for climate information services: evidence from cowpea and sesame producers in Northern Burkina Faso. Sustainability 10:611. doi: $10.3390 /$ su10030611

Padli, J., Habibullah, M. S., and Baharom, A. H. (2018). The impact of human development on natural disaster fatalities and damage: panel data evidence. Econ. Res. Ekonomska IstraŽivanja 31, 1557-1573. doi: 10.1080/1331677X.2018.1504689

Padma, T. (2019). African nations push UN to improve drought research. Nature 573:319. doi: 10.1038/d41586-019-02760-9

Pereira, M. G., Parente, J., Amraoui, M., Oliveira, A., and Fernandes, P. M. (2020). "The role of weather and climate conditions on extreme wildfires," in Extreme Wildfire Events and Disasters, eds F. Tedim, T. K. McGee, and V. Leone (Amsterdam: Elsevier), 55-72. doi: 10.1016/B978-0-12-815721-3.00003-5

Potter, S. H., Kreft, P. V., Milojev, P., Noble, C., Montz, B., Dhellemmes, A., et al. (2018). The influence of impact-based severe weather warnings on risk perceptions and intended protective actions. Int. J. Disast. Risk Reduct. 30, 34-43. doi: 10.1016/j.ijdrr.2018.03.031

Salack, S., Saley, I. A., Lawson, N. Z., Zabré, I., and Daku, E. K. (2018). Scales for rating heavy rainfall events in the West African Sahel. Weather Clim. Extremes 21, 36-42. doi: 10.1016/j.wace.2018.05.004

Schaer, C., and Hanonou, E. K. (2017). The real governance of disaster risk management in peri-urban Senegal: delivering flood response services through co-production. Progr. Dev. Stud. 17, 38-53. doi: 10.1177/1464993416674301

Silvestro, F., Rossi, L., Campo, L., Parodi, A., Fiori, E., Rudari, R., et al. (2019). Impact-based flash-flood forecasting system: sensitivity to high resolution numerical weather prediction systems and soil moisture. J. Hydrol. 572, 388-402. doi: 10.1016/j.jhydrol.2019.02.055

Singh, C., Urquhart, P., and Kituyi, E. (2016). From Pilots to Systems: Barriers and Enablers to Scaling up the Use of Climate Information Services in Smallholder Farming Communities. CARIAA Working Paper no. 3. Ottawa, ON; London: International Development Research Centre. Available online at: www.idrc.ca/ cariaa

Street, R., Buontempo, C., Mysiak, J., Karali, E., Pulquério, M., Murray, V., et al. (2019). How could climate services support disaster risk reduction in the 21st century. Int. J. Disast. Risk Reduct. 34, 28-33. doi: 10.1016/j.ijdrr.2018.1 2.001

Sultan, B., and Gaetani, M. (2016). Agriculture in West Africa in the twenty-first century: Climate change and impacts scenarios, and potential for adaptation. Front. Plant Sci. 7:1262. doi: 10.3389/fpls.2016.01262

Taylor, A. L., Kause, A., Summers, B., and Harrowsmith, M. (2019). Preparing for doris: exploring public responses to impact-based weather warnings in the UK. Weather Clim. Soc. 11, 713-729. doi: 10.1175/WCAS-D-18-0132.1

Thomson, M. C., Muñoz, Á. G., Cousin, R., and Shumake-Guillemot, J. (2018). Climate drivers of vector-borne diseases in Africa and their relevance to control programmes. Infect. Dis. Poverty 7:81. doi: 10.1186/s40249-018-0460-1

UNISDR (2015). "Sendai framework for disaster risk reduction 2015-2030," in Proceedings 773 of the 3rd United Nations World Conference on DRR (Sendai), 14-18. Available online at: https://www.unisdr.org/files/43291_ sendaiframeworkfordrren.pdf (accessed October 1, 2020). 
Vaughan, C., Hansen, J., Roudier, P., Watkiss, P., and Carr, E. (2019). Evaluating agricultural weather and climate services in Africa: evidence, methods, and a learning agenda. Wiley Interdiscip. Rev. Clim. Change 10:e586. doi: $10.1002 /$ wcc. 586

Weyrich, P., Scolobig, A., Bresch, D. N., and Patt, A. (2018). Effects of impactbased warnings and behavioral recommendations for extreme weather events. Weather Clim. Soc. 10, 781-796. doi: 10.1175/WCAS-D-18-0038.1

WMO (2015). WMO Guidelines on Multi-Hazard Impact-Based Forecast and Warning Services. Geneva: WMO. Available online at: https://etrp.wmo.int/ pluginfile.php/16270/mod_resource/content/0/wmo_1150_en.pdf (accessed October 1, 2020).

WMO (2017). "A multi-hazard early warning systems: a checklist," in Outcome of the First Multi-hazard Early Warning Conference 22 to 23 May 2017 - Cancún, Mexico. Prepared by the partners of the International Network for Multi-hazard Early Warning Systems (Geneva). Available online at: https://library.wmo.int/ doc_num.php?explnum_id=4463 (accessed October 1, 2020).

Yang, J., Yang, Y. E., Khan, H. F., Xie, H., Ringler, C., Ogilvie, A., et al. (2018). Quantifying the sustainability of water availability for the water-foodenergy-ecosystem nexus in the niger river basin. Earth's Future 6, 1292-1310. doi: 10.1029/2018EF000923
Zaitchik, B. F. (2017). "Climate and health across Africa," in Oxford Research Encyclopedia of Climate Science. Retrieved from: https://oxfordre.com/ climatescience/view/10.1093/acrefore/9780190228620.001.0001/acrefore9780190228620-e-555 (accessed October 1, 2020).

Zakari, S., Ying, L., and Song, B. (2014). Factors influencing household food security in West Africa: the case of Southern Niger. Sustainability 6, 1191-1202. doi: $10.3390 /$ su6031191

Conflict of Interest: The authors declare that the research was conducted in the absence of any commercial or financial relationships that could be construed as a potential conflict of interest.

Copyright (C) 2020 Nkiaka, Taylor, Dougill, Antwi-Agyei, Adefisan, Ahiataku, Baffour-Ata, Fournier, Indasi, Konte, Lawal and Toure. This is an open-access article distributed under the terms of the Creative Commons Attribution License (CC BY). The use, distribution or reproduction in other forums is permitted, provided the original author(s) and the copyright owner(s) are credited and that the original publication in this journal is cited, in accordance with accepted academic practice. No use, distribution or reproduction is permitted which does not comply with these terms. 